\title{
Direct interfacial polymerization onto thin ceramic hollow fibers
}

\author{
Evelien Maaskant, Patrick de Wit, Nieck E. Benes \\ University of Twente, Faculty of Science and Technology/Mesa + Institute for Nanotechnology, Membrane Science and Technology Cluster - Films in Fluids Group,
} Drienerlolaan 5, 7500 AE Enschede, The Netherlands

\section{A R T I C L E I N F O}

\section{Keywords:}

Inorganic porous hollow fiber

Interfacial polymerization

Polyamide

\begin{abstract}
A B S T R A C T
Membrane separation under harsh conditions, such as high- $p, T$ or in the presence of aggressive chemicals, requires a robust membrane support. In academia commonly ceramic disks are used for this purpose, but these disks posses a too low surface-area-to-volume ratio for practical applications. Ceramic hollow fibers potentially provide a much larger specific surface area, but applying a defect free thin selective layer on such structures is more intricate. Here we show the successful preparation of a thin polyamide layer on a thin porous hollow $\alpha$-alumina fiber by interfacial polymerization of piperazine with trimesoyl chloride. Two aspects of the fabrication method are identified as particularly crucial for obtaining a high quality selective layer: i) the layer the ceramic surface should have a sufficient amount of hydroxyl groups for covalent attachment in order to avoid delamination, and ii) controlled drying steps are necessary to avoid local surplus or lack of liquid on the outer surface of the ceramic. To increase the hydroxyl group concentration, and to facilitate the presence of sufficient reactants in a large volume of small pores, the fibers have been coated with a layer of $\gamma$-alumina. Sufficiently long drying steps $(20 \mathrm{~mm})$ have been employed to avoid uneven drying over the length of the fiber. The obtained fibers show clean water fluxes in the range of $2-5 \mathrm{~L} \mathrm{~m}^{-2} \mathrm{~h}^{-1} \mathrm{bar}^{-1}$ combined with a retention of Rose Bengal above $99 \%$.
\end{abstract}

\section{Introduction}

Interfacial polymerization (IP) is a well-known technique to fabricate extremely thin separation layers on porous supporting structures and has been extensively studied over the past decades [1,2]. Research has been done on preparing thin selective films on porous polymeric supports, such as polyethersulfone or polyetherimide [3-7]. The use of such membranes in harsh conditions can be limited by the stability of the thin selective layer as well as by the stability of the porous support. In applications involving high- $p, T$, or in the presence of aggressive chemicals, polymer supports can suffer from plasticization, swelling, or thermal degradation. The thermal-mechanical-chemical stability of an inorganic porous support avoids such problems. Ceramics have been successfully used as support for thin IP films for applications where the mechanical and thermal stability of the ceramic is required, in for example pervaporation [8] or sieving of hot gases by hybrid inorganicimide polymer networks [9]. In addition, the superior thermal stability of a ceramic support allows for the fabrication of thin IP films that require a thermal treatment, such as the imidization step in the fabrication of the hybrid poly(imide) networks [10]. This opens up new possibilities for IP chemistries for membranes.

Commonly, in academia inorganic supports have the geometry of a flat disk, with a far too low surface-area-to-volume ratio for viable industrial application. Hollow fibers provide a much larger surface-areato-volume ratio $[7,11,12]$ allowing for industrial application [13]. Inorganic porous hollow fibers can be prepared from various materials, for example alumina $\left(\mathrm{Al}_{2} \mathrm{O}_{3}\right)$ [14], titanium dioxide $\left(\mathrm{TiO}_{2}\right)$ [15], or silicon carbide $(\mathrm{SiC})$ [16]. The diameters of such fibers can be as small as $\sim 200 \mu \mathrm{m}$ [17]. Limited research is reported on thin film composite (TFC) membranes, made of interfacial polymerized layers prepared directly atop of porous inorganic hollow fibers. Nearly all IP films on inorganic porous hollow fibers involve the use of a polymeric intermediate layer. For example, a polyethersulfone (PES) repair layer was coated onto a commercially available ceramic tube prior to the IP fabrication of a poly(vinyl alcohol)-piperazine-trimesoyl chloride (PVAPip-TMC) layer [18]. A polymeric coating of polydopamine (PDA) or polyethyleneimine (PEI) was applied onto an alumina fiber with a relatively large outer diameter of $3.7 \mathrm{~mm}$, in order to facilitate the IP fabrication of an m-phenylenediamine-trimesoyl chloride (MPD-TMC) layer [8]. The use of a polymeric repair layer inherently reduces the overall thermo-chemical stability of the final membrane. Peters et al. [19] coated ceramic fibers with an inorganic ( $\gamma$-alumina) intermediate layer, prior to applying a microporous silica layer [19] or a poly(vinyl alcohol) layer [20] via dip-coating. Cao et al. [21] introduced a process

\footnotetext{
* Corresponding author.

E-mail address: n.e.benes@utwente.nl (N.E. Benes).
} 
based on IP assisted dipcoating of nanocrystals on alumina hollow fibers without an intermediate layer. In this elegant concept the polymer produced by IP serves to arrest seed crystals on the support surface in the form of a thin dense layer. This layer does not function as selective membrane but supplies abundant nucleation sites for the secondary growth of a zeolite. [21]

To our knowledge fabrication of a thin defect-free selective film by IP on an entirely inorganic thin porous hollow fiber support has never been reported. We show that it is possible to fabricate a defect-free IP polyamide layer onto an alumina hollow fiber with an outer diameter of $1.5 \mathrm{~mm}$ that is coated with meso-porous inorganic intermediate layers. We have chosen to use a well-known model system for interfacial polymerization, piperazine and trimesoyl chloride, to eliminate the influence of any unknown chemistry. Without optimizing the performance of these fibers, the measured permeances are similar to those of some commercial nanofiltration membranes and IP membranes on polymer hollow fibers supports reported in literature. This demonstrates that an extremely stable fully inorganic porous hollow fiber can be used as a support for a high quality thin film composite membrane. This extends the application range of interfacial polymerized membranes in harsh conditions, and allows to further develop high performance membranes based on novel advanced chemistries. These advanced IP chemistries are presently sporadically investigated due to the limited thermo-chemical stability of porous polymer supports.

\section{Experimental}

\subsection{Chemicals}

AKP-30 $\alpha$-alumina powder $\left(99.9 \% \mathrm{Al}_{2} \mathrm{O}_{3}\right.$, particle size of $0.3 \mu \mathrm{m}$, Sumitomo Chemicals Co. LTD. Japan), polyethersulfone (PES, Ultrason ${ }^{8}$ E6020 P, BASF), and de-ionized water $\left(>18.2 \mathrm{M} \Omega \mathrm{cm}^{-1}\right.$, Milli-Q Advantage A10, Millipore) were used for fiber preparation. Prior to use, PES was dried overnight at $80^{\circ} \mathrm{C}$. Piperazine (Pip, 99\%), n-hexane (anhydrous, 95\%), trimesoyl chloride (TMC, 98\%), Rose Bengal (RB, 95\%), poly(vinyl alcohol) (PVA, Mowiol 8-88, $M_{W} 67,000 \mathrm{gmol}^{-1}$ ), poly(vinyl pyrrolidone) (PVP, $M_{W} \sim 1,300,000$ ), and $N$-methyl-2-pyrrolidone (NMP, <99.5\%) were obtained from Sigma-Aldrich (the Netherlands) and used as received. Nitric acid (1 M) was obtained from Merck and diluted to $0.05 \mathrm{M}$ for further use.

\subsection{Fiber fabrication}

Alumina hollow fiber membranes were prepared by dry-wet spinning based on non-solvent induced phase separation (NIPS) using a well-established method [17]. Briefly, a mixture of AKP-30 $\alpha$-alumina powder, PES, NMP and PVP was spun into a coagulation bath with deionized water functioning as non-solvent. The mixture composition and spinning parameters are listed in Table 1. After thermal treatment

Table 1

Spinning conditions.

\begin{tabular}{ll}
\hline Condition & Value \\
\hline PES & $9.40 \mathrm{wt} \%$ \\
NMP & $40.0 \mathrm{wt} \%$ \\
AKP-30 & $48.9 \mathrm{wt} \%$ \\
PVP K95 & $0.70 \mathrm{wt} \%$ \\
Water & $1.00 \mathrm{wt} \%$ \\
Bore liquid & $\mathrm{H}_{2} \mathrm{O}$ \\
Coagulation bath & $\mathrm{H}_{2} \mathrm{O}$ \\
Extrusion pressure & $2 \mathrm{bar}$ \\
Air gap & $3 \mathrm{~cm}$ \\
Bore liquid flow rate & $7 \mathrm{~mL} \mathrm{~min}{ }^{-1}$ \\
Outer diameter spinneret & $2.0 \mathrm{~mm}$ \\
Inner diameter spinneret & $0.8 \mathrm{~mm}$ \\
Drying after spinning & $>24 \mathrm{~h}$ \\
\hline
\end{tabular}

$\left(300{ }^{\circ} \mathrm{C}\right.$ for $1 \mathrm{~h}, 1400{ }^{\circ} \mathrm{C}$ for $2 \mathrm{~h}$, rate of $5{ }^{\circ} \mathrm{C} \mathrm{min}{ }^{-1}$ ) the fibers were coated with an AKP-30 alumina layer in order to lower the surface roughness. A $50 \mathrm{wt} \%$ suspension of AKP-30 in $0.05 \mathrm{wt} \%$ PVA in $0.02 \mathrm{~mol} \mathrm{HNO}_{3}$ solution is ultrasonic treated to disperse the AKP-30 particles. Prior to coating, one end of the fiber was sealed with hot melt adhesive (Dremel) and the fibers were vertically dip coated with a rate of $0.6 \mathrm{~m} \mathrm{~min}^{-1}$ and a holding time of $30 \mathrm{~s}$. After drying $\left(1 \mathrm{~h}, 25^{\circ} \mathrm{C}\right.$, relative humidity $50-80 \%$ ) the fibers are sintered for $1 \mathrm{~h}$ at $1000^{\circ} \mathrm{C}$ with a heating rate of $5^{\circ} \mathrm{C} \mathrm{min}^{-1}$.

Two layers of $\gamma$-alumina were applied on top of the $\alpha$-alumina fiber to provide enough hydroxyl-groups for covalent attachment of the polyamide layer to the support, and to provide a large volume of small pores for the aqueous phase in the IP process. For each layer of $\gamma$-alumina, $20 \mathrm{~mL}$ of PVA solution (2.25 g PVA in $75 \mathrm{~mL} 0.05 \mathrm{M} \mathrm{HNO}_{3}$ ) and $30 \mathrm{~mL}$ of boehmite sol were mixed. The details of the boehmite synthesis and coating procedure are described elsewhere [22]. The lower end of the fiber was sealed with hot melt adhesive and the fibers were vertically dip coated with a rate of $2.4 \mathrm{~m} \mathrm{~min}^{-1}$, and a holding time of $1 \mathrm{~s}$. After drying $\left(2 \mathrm{~h}, 25^{\circ} \mathrm{C}\right.$, relative humidity $\left.50-80 \%\right)$ and removal of the hot melt adhesive, the $\gamma$-alumina layer is sintered for $1 \mathrm{~h}$ at $600{ }^{\circ} \mathrm{C}$ with a heating rate of $5^{\circ} \mathrm{C} \mathrm{min}^{-1}$.

\subsection{Interfacial polymerization}

Prior to dipcoating, the fibers were sealed at the lower end with a $1.5 \mathrm{~cm}$ long glass tube filled with Araldite 2014-1 (Huntsman) and cured for $24 \mathrm{~h}$ at ambient conditions. There was no further pretreatment applied to the fibers. The fibers were inserted in the aqueous phase containing $2 \mathrm{wt} \%$ piperazine for $1 \mathrm{~min}$, and withdrawn with a vertical dipcoater $\left(9 \mathrm{~m} \mathrm{~min}^{-1}\right)$. The fibers were dried at ambient conditions for $20 \mathrm{~min}$, and inserted for $10 \mathrm{~s}$ in the organic phase $(0.15 \mathrm{wt} \%$ TMC in n-hexane). The fibers were then withdrawn with a speed of $9 \mathrm{~m} \mathrm{~min}^{-1}$, rinsed with acetone to remove any unreacted monomers, and stored under ambient conditions until further use.

\subsection{Module fabrication}

The final fiber was glued (Araldite 2014, Huntsman) in a 1/4" piece of metal tubing that acts as the membrane outlet, whereas the other side of the fiber was already glued using an Araldite filled glass cap. The fiber is enclosed with a metal tube and connected to a T-piece for permeate/retentate streams. Fig. 1 shows a schematic overview of the potted fiber and how the module assembly is connected to the setup for permeation experiments.

\subsection{Characterization methods}

Scanning electron micrographs of the cross-section and top view morphology of green, sintered, and TFC fibers were obtained with a Zeiss Merlin FE-SEM or JEOL-JSM6010 scanning electron microscope. Samples were coated with a $10 \mathrm{~nm}$ chromium layer (Quorum Q150T ES). The outer diameter of the fibers was measured using a Nikon V-12 profile projector with a $50 \times$ objective lens (Nippon Kogaku, Japan). 18 samples originating from 3 different fibers were analyzed and the average diameter was taken for flux calculations. Clean water fluxes were measured in a custom-build setup (Convergence, the Netherlands) in dead-end operation with pressures ranging from 8 to 18 bar applied to an outside-in-geometry. The permeate volume was measured over time volumetrically. Rose Bengal retention $(35 \mu \mathrm{mol}$ in water) was measured at a custom-made dead-end filtration setup. The feed was pressurized with nitrogen to 18 bar applied to an outside-in geometry. Solute concentrations of the feed and permeate streams were measured with an UV-vis spectrophotometer at $549 \mathrm{~nm}$ (Varian Cary 300 scan). The retention was calculated as: 

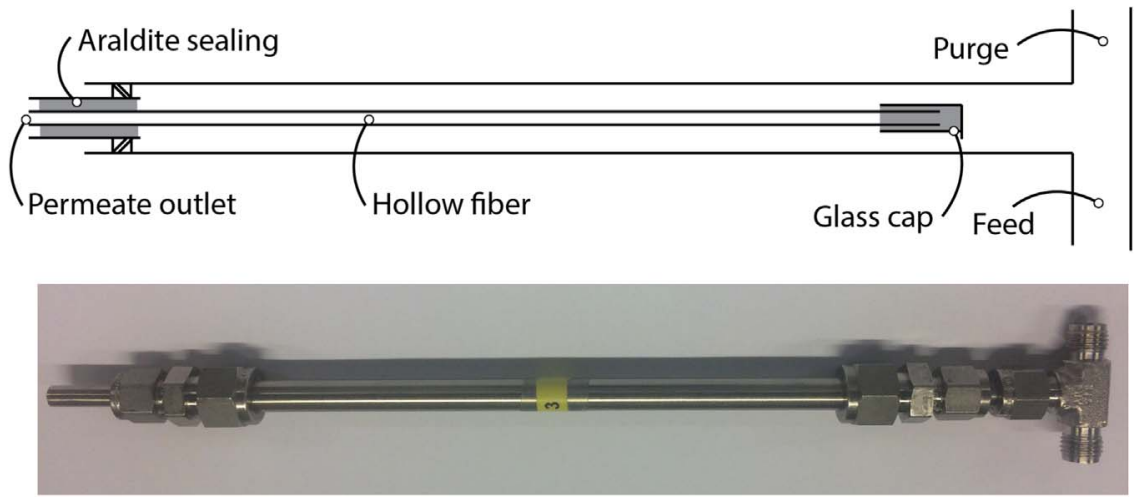

Fig. 1. Schematic overview of membrane potting and assembly of the module.
$R=\frac{c_{f}-c_{p}}{c_{f}} \cdot 100 \%$

\section{Results and discussion}

\subsection{Fiber fabrication and coating}

The $\alpha$-alumina fibers prepared by dry-wet spinning based on NIPS have pores in the range of $350 \mathrm{~nm}$ (not shown here, see [23]). The fibers were coated with an AKP-30 smoothing layer by vertical dipcoating to reduce the pore size to approximately $100 \mathrm{~nm}$, and to eliminate the presence of macrovoids close to or reaching the surface. Zhang et al. [24] showed the possibility of film formation beyond the length scale of the AKP-30 pores, when the liquid-liquid interface is well defined.

Fig. 2A and B show top-view scanning electron micrographs of a layer prepared directly on the AKP-30 smoothing layer. A polyamide film is present covering most parts of the surface, while clear patches of the ceramic support are still visible. It is hypothesized that this delamination is for a large part due the insufficient drying of the fiber after being in contact with the aqueous phase. An excess of aqueous solution may shield of the fiber surface from the reactant in the organic phase, causing film formation to occur at a slight distance from the fiber surface and prohibiting the surface hydroxyl groups to partake in the polymerization reaction. A sufficiently long drying time is required to avoid that excess aqueous solution is present on the outer surface of the fiber, but the drying is complicated by the relative large pores $(100 \mathrm{~nm})$ and low porosity (30\%) of the AKP-30 intermediate layer. The capillary forces inside the large pores can be too small to counter the gravitational force, hence it affects the ability to contain the aqueous phase inside the porous structure. In addition, the surface roughness of the fiber could play a role. Ogieglo et al. [25] showed that the surface roughness of a flat polished AKP-30 surface is already of the order of a standard polyamide film thickness. This surface roughness could prevent the formation of a stable well-defined interface. Finally, even if a well defined film could be formed, sufficient hydroxyl groups are required to prevent delamination.

To increase the amount of hydroxyl groups [26], and to allow for a larger reactant reservoir in $\sim 5 \mathrm{~nm}$ small pores, the fibers were coated with $\gamma$-alumina atop of the AKP-30 smoothing layer. The use of $\gamma$-alumina intermediate layers has been studied elaborately for, for instance, the fabrication of high performance inorganic gas separation membranes [27]. Initial tests have been done in this study to find the appropriate dip-coating velocity and hold-down time, and the minimum required number of $\gamma$-alumina layers. After applying the initial $\gamma$-alumina layer there are still some uncovered AKP-30 spots present on the surface (data not shown) that prevent a proper layer attachment due to their relatively large size. Applying a second $\gamma$-alumina layer results in a coating that completely covers of the $\alpha$-alumina layer. The remaining small sized minor defects do not prevent the formation of an attached polyamide film.

Fig. 3A to D show the successful coating of an gamma-coated alumina NIPS hollow fiber. Panel A shows the outside of the NIPS fiber wall on which the AKP-30 smoothing layer is coated. Since the AKP-30 layer is not coated by a NIPS process, there are no macrovoids present, resulting in a smooth fiber wall. Panel B shows a detail image of two $\gamma$-alumina layers on the AKP-30 smoothing layer. It can be seen that the thickness of the two $\gamma$-alumina layers is in the order of a few hundred $\mathrm{nm}$. Fig. 3C and D show a high resolution image of the $\gamma$-alumina layer, without (panel C) and with (panel D) the TMC-Pip layer present. The TMC-Pip membrane is a relatively thin film $(\sim 100 \mathrm{~nm})$, as is expected for these polyamide films.

The $\gamma$-alumina coated fibers were submerged in the aqueous phase to fill the porous structure with piperazine monomer. The drying procedure after this step appears to be an important factor for successful preparation of well attached polyamide films. Fig. 4 shows the influence of the drying time at ambient conditions on the adhesion of the TMC-Pip layer to the gamma-coated alumina support. Top view scanning electron micrographs were taken at the top and the bottom of the fiber after 10 and 20 min drying. Since the fibers were vertically dried,

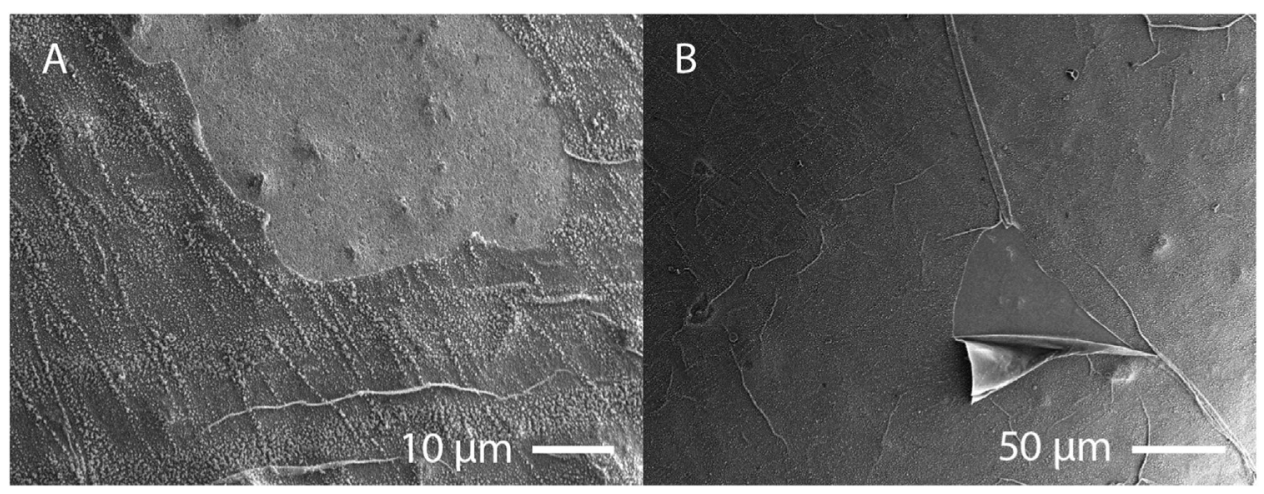

Fig. 2. (A) and (B) Scanning electron micrographs (top view) of a TMC-Pip film on an AKP-30 smoothed fiber. A polyamide film is present covering parts of the surface, but also clear patches of the ceramic support are visible. 


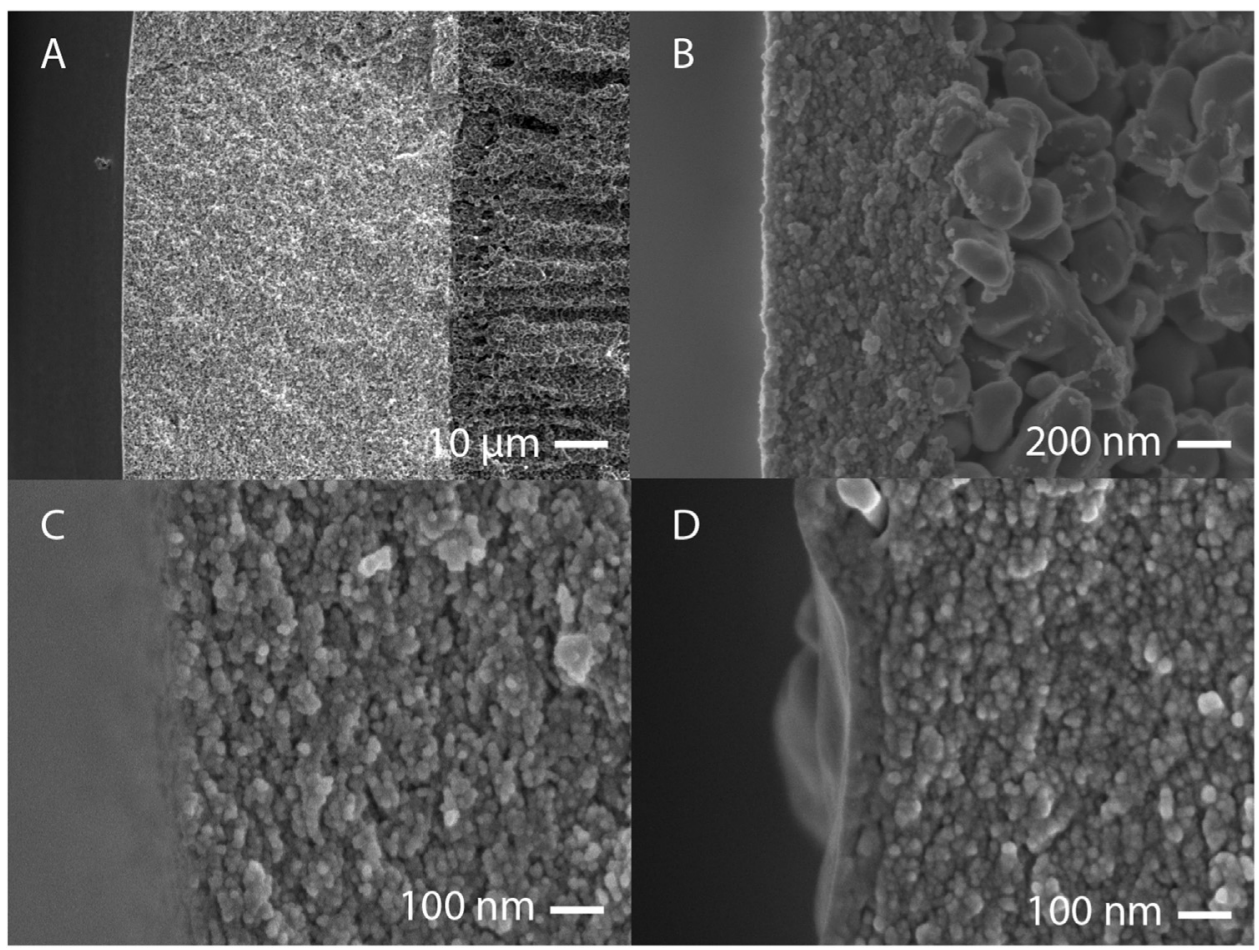

Fig. 3. Cross-section scanning electron micrographs of the wall of an $\alpha$-alumina fiber. Panel A shows the AKP-30 smoothing layer atop of a NIPS alumina fiber. Panel B shows the $\gamma$-alumina layer atop of the AKP-30 smoothing layer. The thickness of the two $\gamma$-alumina layers is in the order of a few hundred $\mathrm{nm}$. Panel C and D show a high resolution image of the $\gamma$-alumina layers without (C) and with (D) the TMC Pip film. The TMC-Pip film has a thickness of around $100 \mathrm{~nm}$.

the amount of residual water is expected to be higher at the bottom of the fiber. There is a significant difference in film morphology at the top and bottom of the fiber after $10 \mathrm{~min}$ of drying (Fig. 4A and C). The polyamide film at the bottom of the fiber showed to be a freestanding film with huge defects due to the presence of a film of excess water on the outer surface of the fiber. The top of the fiber does not show the ceramic structure, although there is no smooth continuous film visible. However, 20 min of drying does result in a well-attached continuous film on both the top and bottom side of the fiber. There are still some minor differences in film morphology at the top and bottom of the fiber, probably due to small differences in local reaction conditions, but these are not expected to excessively affect the membrane performance.

\subsection{Retention and permeation}

In total 13 fibers with a length over $12 \mathrm{~cm}$ have been fabricated and used for performance testing. Table 2 shows the results of these measurements. One of the 13 fibers broke during potting. The remaining 12 fibers have been tested for their clean water permeance and Rose Bengal retention. Three fibers showed a poor retention and high

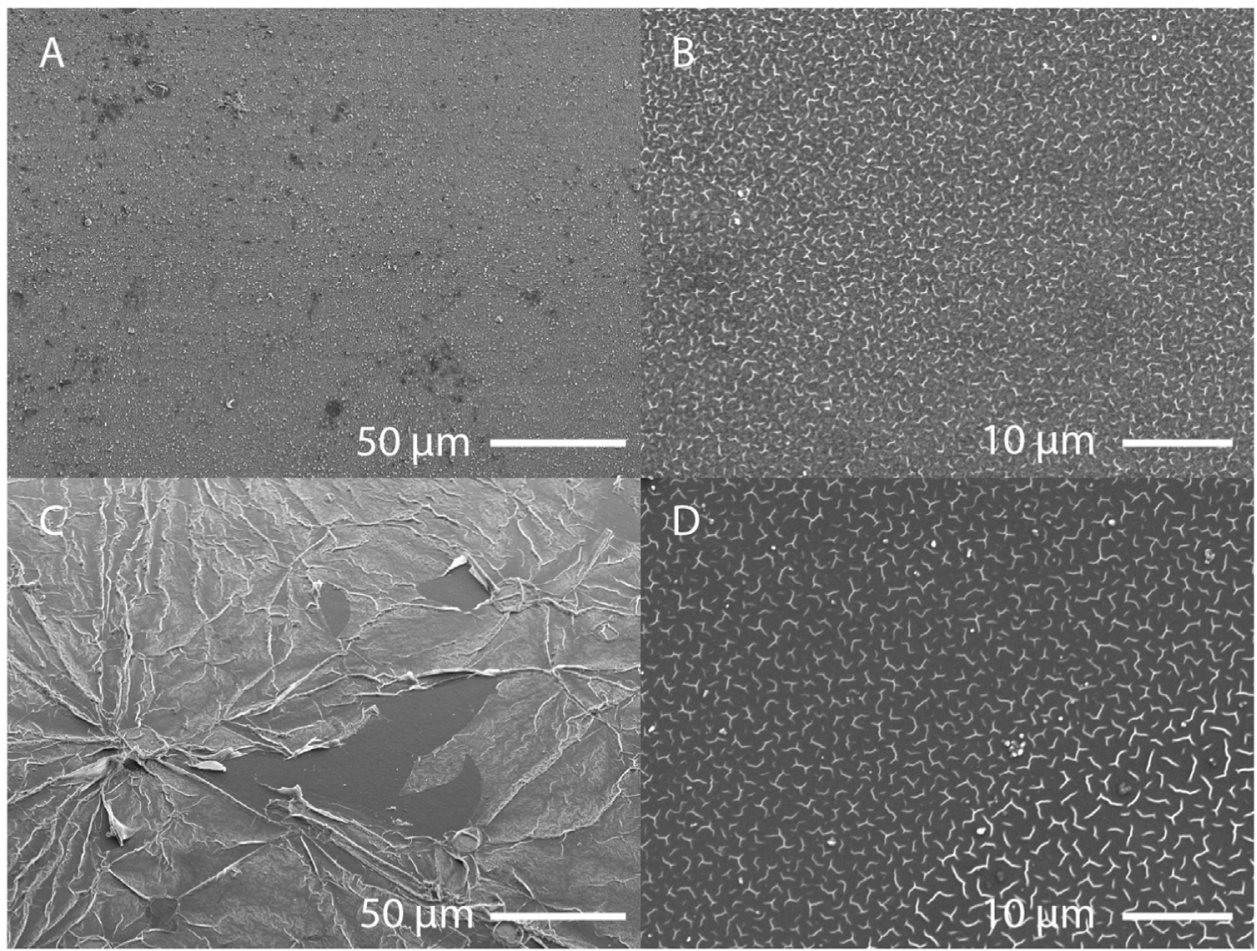

Fig. 4. Top-view scanning electron micrographs of the TMC-Pip polyamide films. Micrographs were taken on the top (A and B) of the bottom (C and D) of the hollow fiber. The fiber shown in panel $A$ and $C$ was dried for $10 \mathrm{~min}$, the fiber shown in panel B and D for $20 \mathrm{~min}$. An unattached, freestanding film has formed at the bottom of the fiber after $10 \mathrm{~min}$ of drying, while after $20 \mathrm{~min}$ the film is well-attached to the fiber surface. 
Table 2

The performance of 13 TMC-Pip fibers prepared using 20 min drying time at ambient conditions, on hollow fiber supports coated with two $\gamma$-layers. The clean water permeance (CWP) was measured for six pressures varying from 8 to 18 bar. The CWP given is based on a linear fit of the permeance versus pressure. For comparison also the results of an $\gamma$-alumina fiber (indicated with $\#=\gamma$ ) are shown.

\begin{tabular}{llll}
\hline$\#$ & $\begin{array}{l}\text { Length } \\
(\mathrm{cm})\end{array}$ & $\begin{array}{l}\text { Retention } \\
(\%)\end{array}$ & $\begin{array}{l}\mathrm{CWP} \\
\left(\mathrm{L} \mathrm{m}^{\mathrm{a}} \mathrm{h}^{-1} \mathrm{bar}^{-1}\right)\end{array}$ \\
\hline$\gamma$ & 10.2 & $61.6 \pm 1$ & $17.4 \pm 0.8$ \\
1 & 14.1 & $\mathrm{n} / \mathrm{m}^{\mathrm{c}}$ & $\mathrm{n} / \mathrm{m}^{\mathrm{c}}$ \\
2 & 13.7 & $99.8 \pm 1$ & $3.9 \pm 0.1$ \\
3 & 13.6 & $97.9 \pm 1$ & $3.8 \pm 0.3$ \\
4 & 13.9 & $\mathrm{n} / \mathrm{m}^{\mathrm{c}}$ & $\mathrm{n} / \mathrm{m}^{\mathrm{c}}$ \\
5 & Broken & & \\
6 & 13.7 & $99.8 \pm 1$ & $3.2 \pm 0.3$ \\
7 & 13.1 & $99.7 \pm 1$ & $2.3 \pm 0.2$ \\
8 & 13.2 & $99.9 \pm 1$ & $5.0 \pm 0.3$ \\
9 & 14.7 & $99.8 \pm 1$ & $4.1 \pm 0.5$ \\
10 & 13.0 & $\mathrm{n} / \mathrm{m}^{\mathrm{c}}$ & $\mathrm{n} / \mathrm{m}^{\mathrm{c}}$ \\
11 & 12.8 & $99.9 \pm 1$ & $3.3 \pm 0.3$ \\
12 & 14.7 & $100.0 \pm 1$ & $4.7 \pm 0.7$ \\
13 & 12.9 & $99.6 \pm 1$ & $4.0 \pm 0.2$ \\
\hline
\end{tabular}

a The given uncertainty is an estimate of the measurement error.

b Clean Water Permeance with 95\% confidence interval, based on linear regression of the measured permeance and pressure.

${ }^{c}$ Flux was in the order of an unmodified fiber, omitted from further analysis.

d This fiber broke during potting.

permeance and have been omitted from further analysis. This indicates that even due to careful surface pre-treatment, still minor defects can be present. These defects might not necessarily be in the TMC-Pip layer itself, but can also arise from fiber handling during the coating steps, or from handling during potting of the fiber. The remaining nine fibers show acceptable permeances and good Rose Bengal retention. The clean water permeance is in the order of $2-5 \mathrm{~L} \mathrm{~m}^{-2} \mathrm{~h}^{-1} \mathrm{bar}^{-1}$ with an average $3.8 \mathrm{~L} \mathrm{~m}^{-2} \mathrm{~h}^{-1} \mathrm{bar}^{-1}$ ). The clean water permeances are slightly lower as values reported in literature for TMC-Pip membranes on polymeric supports (Table 3. This can be explained by the small rigid pores present in the $\gamma$-alumina layer. The nanoconfinement of a polyamide network in these small rigid pores could lead to lower chain dynamics [35], and hence lower water fluxes.

The prepared fibers showed excellent retention ( $>99 \%$ ) for Rose Bengal in water, as compared to a retention of $61.6 \%$ for a fiber with only two $\gamma$-alumina layers. Even without optimizing the IP process with respect to performance, the permeance of the fibers approaches that of some commercial membranes and of some polymer supported IP membranes presented in literature. The significant increment of rose bengal retention demonstrates the feasibility of fabricating defect free ceramic supported thin film composite membranes, which opens many possibilities for developing IP membranes for harsh conditions or IP membranes based on new chemistries involving thermal or otherwise demanding steps.

\section{Conclusion}

In this paper we demonstrated a method to make an TFC membrane on a completely inorganic hollow fiber support. By modification of an alumina fiber, prepared by dry-wet spinning, with an AKP-30 smoothing layer using dip coating, a sufficiently smooth surface is obtained to allow the formation of TMC-pip thin films. In order to improve the chemical bonding to the support, sufficient hydroxyl-groups are required, which can be obtained by coating two layers of $\gamma$-alumina onto the fiber. This, combined with appropriate drying of the fiber after it has been soaked with the aqueous phase, allows for defect free thin films to be obtained. The TFC fibers show promising water permeance values (average $3.8 \mathrm{~L} \mathrm{~m}^{-2} \mathrm{~h}^{-1} \mathrm{bar}^{-1}$ ) with good retention of Rose Bengal (1017 $\mathrm{gmol}^{-1}$ ).

Out of 12 tested fibers, with a length over $12 \mathrm{~cm}$, nine fibers are completely defect free. The other three fibers showed a lower retention or high flux. Despite careful surface pre-treatment, still minor defects can be present. These defects may not necessarily be located in the TMC-Pip layer itself, but can also arise from fiber handling or fiber potting and sealing. To conclude, this study shows that thin inorganic porous hollow fibers can indeed be a suitable support for layers prepared by interfacial polymerization and that the pre-treatment of the fiber is of key importance in order to allow proper adhesion of the layer. The results obtained in this study can aid fabrication of thin films on inorganic porous hollow fibers with more advanced chemistry, which can promote industrial application of these layers on an industrial scale under harsh conditions.

\section{Acknowledgements}

This research is supported by the Dutch Technology Foundation STW (Project no. 12543), which is part of the Netherlands Organisation for Scientific Research (NWO), and which is partly funded by the Ministry of Economic Affairs. Parts of this work have been carried out within the framework of the Institute for Sustainable Process Technology (ISPT, project BL-20-02).

Table 3

Permeances of TMC-Pip membranes reported in literature on both flat sheet and hollow fiber polymeric supports. Some commercial available membranes are added for comparison.

\begin{tabular}{|c|c|c|c|c|c|c|}
\hline $\begin{array}{l}\text { Pip conc. } \\
\text { (w/v\%) }\end{array}$ & $\begin{array}{l}\text { TMC conc. } \\
(\mathrm{w} / \mathrm{v} \%)\end{array}$ & Support & $\begin{array}{l}\text { Pressure } \\
\text { (bar) }\end{array}$ & $\begin{array}{l}\text { Flux } \\
\left(L \mathrm{~m}^{-2} \mathrm{~h}^{-1}\right)\end{array}$ & $\begin{array}{l}\text { Permeance } \\
\left(\mathrm{L} / \mathrm{m}^{2} / \mathrm{h} / \mathrm{bar}\right)\end{array}$ & Ref. \\
\hline 2 & 0.1 & PES, flat sheet & 10.4 & 160 & $15.4^{\mathrm{a}}$ & [28] \\
\hline 2 & 0.15 & PSf, flat sheet & 6 & 61 & 10.2 & [29] \\
\hline 2 & 0.15 & PES, flat sheet & 6 & 64 & 10.7 & [29] \\
\hline 2 & 0.15 & PEI, flat sheet & 6 & 85 & 14.2 & [29] \\
\hline 2 & $0.2 \mathrm{wt} \%$ & PES, flat sheet & 10 & 126 & 12.6 & [30] \\
\hline 1 & $0.05 w t \%$ & PAN, flat sheet & & & 7.2 & [31] \\
\hline 1 & Not given & PPESK, hollow fiber & 3.5 & 35 & $10.0^{\mathrm{b}}$ & [32] \\
\hline 0.2 & $0.15 w t \%$ & PSf, hollow fiber & 7 & $32-40$ & $4.6^{\mathrm{c}}-5.7^{\mathrm{a}}$ & [33] \\
\hline Nitto Denko & NTR-7250 & & & & 4 & [34] \\
\hline GE/Osmonics & Desal 5DK & & & & 5.5 & [34] \\
\hline Dow/Filmtec & NF90 & & & & $6.4^{\mathrm{d}}$ & [34] \\
\hline Dow/Filmtec & NF270 & & & & $11^{\mathrm{c}}-13^{\mathrm{d}}$ & [34] \\
\hline
\end{tabular}

\footnotetext{
${ }^{\text {a }}$ Measured with $\mathrm{NaCl}$ solution instead of water.

b Measured with $\mathrm{NaSO}_{4}$ solution instead of water.

${ }^{c}$ Measured with $\mathrm{MgSO}_{4}$ solution instead of water.

${ }^{\mathrm{d}}$ Measured with $\mathrm{CaCl}_{2}$ solution instead of water.
} 


\section{References}

[1] M.J.T. Raaijmakers, N.E. Benes, Current trends in interfacial polymerization chemistry, Prog. Polym. Sci. 63 (2015) 86-142.

[2] W. Lau, A. Ismail, N. Misdan, M. Kassim, A recent progress in thin film composite membrane: a review, Desalination 287 (2012) 190-199.

[3] W. Fang, L. Shi, R. Wang, Mixed polyamide-based composite nanofiltration hollow fiber membranes with improved low-pressure water softening capability, J. Membr. Sci. 468 (2014) 52-61.

[4] R.-X. Zhang, T. Liu, L. Braeken, Z. Liu, X.-L. Wang, B. Van der Bruggen, A design of composite hollow fiber membranes with tunable performance and reinforced mechanical strength, J. Appl. Polym. Sci. 132 (2015) 41247-41256.

[5] X. Wei, S. Wang, Y. Shi, H. Xiang, J. Chen, B. Zhu, Characterization of a positively charged composite nanofiltration hollow fiber membrane prepared by a simplified process, Desalination 350 (2014) 44-52.

[6] D. Hua, Y.K. Ong, P. Wang, T.-S. Chung, Thin-film composite tri-bore hollow fiber (tfc tbhf) membranes for isopropanol dehydration by pervaporation, J. Membr. Sci. 471 (2014) 155-167.

[7] S. Verssimo, K.-V. Peinemann, J. Bordado, New composite hollow fiber membrane for nanofiltration, Desalination 184 (2005) 1-11 (Desalination and the Environment Desalination and the Environment).

[8] G.M. Shi, T.-S. Chung, Thin film composite membranes on ceramic for pervaporation dehydration of isopropanol, J. Membr. Sci. 448 (2013) 34-43.

[9] M.J.T. Raaijmakers, M.A. Hempenius, P.M. Schön, G.J. Vancso, A. Nijmeijer, M. Wessling, N.E. Benes, Sieving of hot gases by hyper-cross-linked nanoscale-hybrid membranes, J. Am. Chem. Soc. 136 (2014) 330-335.

[10] M.J.T. Raaijmakers, E.J. Kappert, A. Nijmeijer, N.E. Benes, Thermal imidization kinetics of ultrathin films of hybrid poly(POSS-imide)s, Macromolecules 48 (2015) 3031-3039.

[11] P. Kosaraju, K. Sirkar, Interfacially polymerized thin film composite membranes on microporous polypropylene supports for solvent-resistant nanofiltration, J. Membr. Sci. 321 (2008) 155-161.

[12] S. Dutczak, C. Tanardi, K. Kopeć, M. Wessling, D. Stamatialis, Chemistry in a spinneret to fabricate hollow fibers for organic solvent filtration, Sep. Purif. Technol. 86 (2012) 183-189.

[13] I. Moch, Membranes, Hollow-fiber, in: Kirk-Othmer Encycl. Chem. Technol., John Wiley \& Sons, Inc., 2000.

[14] B. Kingsbury, K. Li, A morphological study of ceramic hollow fibre membranes, J. Membr. Sci. 328 (2009) 134-140.

[15] T. Zhao, Z. Liu, K. Nakata, S. Nishimoto, T. Murakami, Y. Zhao, L. Jiang, A. Fujishima, Multichannel TiO2 hollow fibers with enhanced photocatalytic activity, J. Mater. Chem. 20 (2010) 5095.

[16] P. de Wit, E.J. Kappert, T. Lohaus, M. Wessling, A. Nijmeijer, N.E. Benes, Highly permeable and mechanically robust silicon carbide hollow fiber membranes, J. Membr. Sci. 475 (2015) 480-487.

[17] M.W.J. Luiten-olieman, M.J.T. Raaijmakers, L. Winnubst, T.C. Bor, M. Wessling, A. Nijmeijer, N.E. Benes, Towards a generic method for inorganic porous hollow fibers preparation with shrinkage-controlled small radial dimensions, applied to Al2O3, Ni, SiC, stainless steel, and YSZ, J. Membr. Sci. 407-408 (2012) 155-163.

[18] L.-Y. Chu, S. Wang, W.-M. Chen, Surface modification of ceramic-supported polyethersulfone membranes by interfacial polymerization for reduced membrane fouling, Macromol. Chem. Phys. 206 (2005) 1934-1940.

[19] T.A. Peters, J. Fontalvo, M.A.G. Vorstman, N.E. Benes, R.A. Van Dam, Z.A.E.P. Vroon, E.L.J. Van Soest-Vercammen, J.T.F. Keurentjes, Hollow fibre microporous silica membranes for gas separation and pervaporation: synthesis, per formance and stability, J. Membr. Sci. 248 (2005) 73-80.

[20] T. Peters, N. Benes, H. Buijs, F. Vercauteren, J. Keurentjes, Thin high flux ceramicsupported PVA membranes, Desalination 200 (2006) 37-39.

[21] Y. Cao, M. Wang, Z.-1. Xu, X.-h. Ma, S.-m. Xue, A novel seeding method of interfacial polymerization-assisted dip coating for the preparation of zeolite naa membranes on ceramic hollow fiber supports, ACS Appl. Mater. Interfaces 8 (2016) 25386-25395 (PMID: 27603411).

[22] R. Uhlhorn, M. Huis in't Veld, K. Keizer, A. Burggraaf, Synthesis of ceramic membranes, J. Mater. Sci. Lett. 27 (1992) 527-537.

[23] P. de Wit, F.S. Daalen, N.E. Benes, The mechanical strength of inorganic porous hollow fibers, J. Membr. Sci. 524 (2017) 721-728.

[24] Y. Zhang, N.E. Benes, R.G.H. Lammertink, Visualization and characterization of interfacial polymerization layer formation, Lab Chip 15 (2015) 575-580.

[25] W. Ogieglo, H. Wormeester, M. Wessling, N. Benes, Spectroscopic ellipsometry analysis of a thin film composite membrane consisting of polysulfone on a porous -alumina support, ACS Appl. Mater. Interfaces 4 (2012) 935-943.

[26] H. Cochrane, R. Rudham, Heats of immersion of alpha and gamma alumina, Trans. Faraday Soc. 61 (1965) 2246-2254.

[27] R.M. de Vos, H. Verweij, High-selectivity, high-flux silica membranes for gas separation, Science 279 (1998) 1710-1711.

[28] N. Saha, S. Joshi, Performance evaluation of thin film composite polyamide nanofiltration membrane with variation in monomer type, J. Membr. Sci. 342 (2009) 60-69.

[29] N. Misdan, W. Lau, A. Ismail, T. Matsuura, D. Rana, Study on the thin film composite poly(piperazine-amide) nanofiltration membrane: impacts of physicochemical properties of substrate on interfacial polymerization formation, Desalination 344 (2014) 198-205.

[30] M. Jahanshahi, A. Rahimpour, M. Peyravi, Developing thin film composite poly (piperazine-amide) and poly(vinyl-alcohol) nanofiltration membranes, Desalination 257 (2010) 129-136.

[31] M. Dalwani, N.E. Benes, G. Bargeman, D. Stamatialis, M. Wessling, Effect of ph on the performance of polyamide/polyacrylonitrile based thin film composite membranes, J. Membr. Sci. 372 (2011) 228-238.

[32] F. Yang, S. Zhang, D. Yang, X. Jian, Preparation and characterization of polypiperazine amide/ppesk hollow fiber composite nanofiltration membrane, $\mathrm{J}$. Membr. Sci. 301 (2007) 85-92.

[33] H. Li, W. Wang, Y. Zhang, Preparation and characterization of high-selectivity hollow fiber composite nanofiltration membrane by two-way coating technique, J. Appl. Polym. Sci. 131 (2014) 41187-41198.

[34] G. Bargeman, J. Westerink, C. Manuhutu, A. ten Kate, The effect of membrane characteristics on nanofiltration membrane performance during processing of practically saturated salt solutions, J. Membr. Sci. 485 (2015) 112-122.

[35] S. Napolitano, A. Pilleri, P. Rolla, M. Wübbenhorst, Unusual deviations from bulk behavior in ultrathin films of poly(tert-butylstyrene): can dead layers induce a reduction of Tg? ACS Nano 4 (2010) 841-848. 